\title{
Putting a stop to organ trafficking and tourism
}

I

If you required an organ transplant and a donor was not currently available, would you be willing to buy the organ you needed? That was the question that Mohamed Sayegh (Figure 1), director of the Transplantation Research Center at Harvard Medical School, posed in a session entitled "No to organ trafficking and tourism: an in-depth discussion regarding the Declaration of Istanbul" at Renal Week 2008, the American Society of Nephrology Annual Meeting.

Although no one in the room answered in the affirmative, all four members of the discussion panel - physician-scientists based in the United States and Canada - said that they see patients who have traveled abroad to be transplanted with kidneys that they have purchased. All the panel members agreed that they would now be very vocal in telling patients that this is not something they should consider. However, they all admitted that before they got involved with the Declaration of Istanbul, this might not have been the case. As Sayegh put it, before he learned more about the subject and became a member of the Steering Committee of the Istanbul Summit, he had always thought, so what? The recipient gets a kidney and the donor gets much-needed money.

The Declaration of Istanbul on Organ Trafficking and Transplant Tourism (1) is the result of a summit in Istanbul convened by The Transplantation Society and the International Society of Nephrology to discuss organ trafficking, transplant tourism, and transplant commercialism. Although organ transplantation has prolonged and improved the lives of many people throughout the world, there is a widespread shortage of donors, which is one of the main factors that has led to the global problems of organ trafficking and transplant tourism. The WHO has estimated that approximately $10 \%$ of organ transplants performed throughout the world involve these practices. However, this percentage is much higher in many developing countries: one study indicates that by 2006, two-thirds of the 2,000 kidney transplants performed in Pakistan were for foreign recipients, most of whom came from the Middle East and South
Asia, as well as some from Europe and North America (2).

Organ vendors mainly come from vulnerable populations, and particularly from impoverished populations in developing countries such as Pakistan, the Philippines, and Colombia. Sayegh said that in drafting the Declaration of Istanbul, members of the steering committee had paid utmost attention to the concerns and issues raised by representatives from the countries most affected by the problem. Ultimately, the Declaration was agreed upon by consensus among the 150 participants in the summit

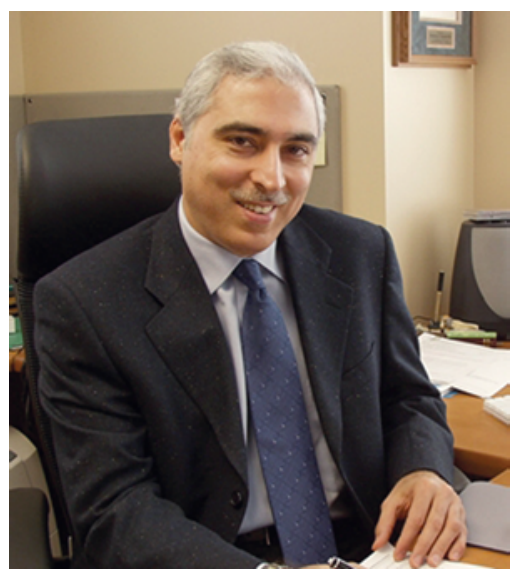

\section{Figure 1}

Mohamed Sayegh is a member of the steering committee that drafted the Declaration of Istanbul on Organ Trafficking and Transplant Tourism.

- individuals (physicians and scientists, representatives of governmental and social agencies, social scientists, legal scholars, and ethicists) from all but one of the 79 countries that perform kidney transplants.

Key to the Declaration are its definitions of the activities it seeks to combat: organ trafficking, transplant commercialism, and transplant tourism (1). However, Sayegh told the JCI that the most important issues raised in the Declaration are those that address how to implement it, and that central to implementation is communication with the many groups involved, including physicians, medical societies, government agencies, pharma- ceutical companies, and funding bodies. Sayegh stressed that much of the work that has been going on in the months since the Declaration was finalized has been to ensure that there is a defined strategy to implement it.

As part of the way forward, Sayegh said that the steering committee is in the process of forming a Custodian Group that will oversee the implementation of the Declaration. There are also a number of task forces being convened, which will communicate with medical societies, pharmaceutical companies, and funding bodies to develop rules by which each entity should abide and to determine the consequences of not adhering to the rules. The goal is to ensure that those involved in organ trafficking are no longer accepted by their respective communities and will therefore find it much harder to continue the practice. Sayegh also noted that the Custodian Group is hoping to connect with journals to further develop ethical policies that have the same effect.

Other task forces have already been deployed to talk to government agencies in areas that are known hotspots for organ trafficking and transplant tourism. Sayegh said that through the strong local networks that are being built, they have received feedback about the activities going on in these regions, and that in some instances the individuals involved have been sanctioned by the medical societies to which they belong.

Despite the achievements so far, Sayegh was keen to point out to the JCI that the Declaration of Istanbul is not going to make organ trafficking disappear. He likened it to drug trafficking, saying that because money is involved it is impossible to eradicate. However, he promised that the Custodian Group will do everything it possibly can to curb the practice and make life hard for those involved.

\section{Karen Honey}

1. Steering Committee of the Istanbul Summit. 2008. Organ trafficking and transplant tourism and commercialism: the Declaration of Istanbul. Lancet. 372:5-6.

2. Naqvi, S.A., Ali, B., Mazhar, F., Zafar, M.N., and Rizvi, S.A. 2007. A socioeconomic survey of kidney vendors in Pakistan. Transpl. Int. 20:934-939. 